\title{
Nontoxic Nep1-Like Proteins of the Downy Mildew Pathogen Hyaloperonospora arabidopsidis: Repression of Necrosis-Inducing Activity by a Surface-Exposed Region
}

\author{
Adriana Cabral, ${ }^{1}$ Stan Oome, ${ }^{1,2}$ Nick Sander, ${ }^{1}$ Isabell Küfner, ${ }^{3}$ Thorsten Nürnberger, ${ }^{3}$ and \\ Guido Van den Ackerveken ${ }^{1,2}$ \\ ${ }^{1}$ Plant-microbe interactions, Department of Biology, Utrecht University, Padualaan 8, $3508 \mathrm{CH}$ Utrecht, The Netherlands; \\ ${ }^{2}$ Centre for BioSystems Genomics (CBSG), Wageningen University, Binnenhaven 5, 6709 PD Wageningen, The Netherlands; \\ ${ }^{3}$ Zentrum für Molekularbiologie der Pflanzen-Pflanzenbiochemie, Eberhard-Karls-Universität Tübingen, Auf der Morgenstelle \\ 5, D-72076 Tübingen, Germany
}

Submitted 17 October 2011. Accepted 27 December 2011.

The genome of the downy mildew pathogen Hyaloperonospora arabidopsidis encodes necrosis and ethylene-inducing peptide 1 (Nep1)-like proteins (NLP). Although NLP are widely distributed in eukaryotic and prokaryotic plant pathogens, it was surprising to find these proteins in the obligate biotrophic oomycete $H$. arabidopsidis. Therefore, we analyzed the $H$. arabidopsidis $N L P(H a N L P)$ family and identified $12 \mathrm{HaNLP}$ genes and 15 pseudogenes. Most of the 27 genes form an $\boldsymbol{H}$. arabidopsidis-specific cluster when compared with other oomycete $N L P$ genes, suggesting this class of effectors has recently expanded in $\boldsymbol{H}$. arabidopsidis. HaNLP transcripts were mainly detected during early infection stages. Agrobacterium tumefaciens-mediated transient expression and infiltration of recombinant NLP into tobacco and Arabidopsis leaves revealed that all HaNLP tested are noncytotoxic proteins. Even HaNLP3, which is most similar to necrosis-inducing NLP proteins of other oomycetes and which contains all amino acids that are critical for necrosisinducing activity, did not induce necrosis. Chimeras constructed between HaNLP3 and the necrosis-inducing PsojNIP protein demonstrated that most of the HaNLP3 protein is functionally equivalent to PsojNIP, except for an exposed domain that prevents necrosis induction. The early expression and species-specific expansion of the $H a N L P$ genes is suggestive of an alternative function of noncytolytic NLP proteins during biotrophic infection of plants.

Oomycetes form a unique branch of eukaryotic microorganisms and comprise a number of economically important and destructive plant pathogens, including the downy mildews and species of the genus Phytophthora. Parasitic lifestyles of these plant pathogens are very diverse, ranging from necrotrophic (feeding on killed plant tissue) to obligate biotrophic (requiring living host tissue for growth and reproduction) (Agrios 2005).

The downy mildew Hyaloperonospora arabidopsidis is an obligate biotrophic pathogen of the model plant Arabidopsis

Nucleotide sequence data for the HaNLP genes are available in the GenBank database under accession numbers JQ027034 to JQ027045.

Corresponding author: Guido Van den Ackerveken;

E-mail: g.vandenackerveken@uu.nl

* The $e$-Xtra logo stands for "electronic extra" and indicates six supplementary figures and two supplementary tables are published online. thaliana. After tissue penetration, $H$. arabidopsidis forms intercellular hyphae, from which haustoria (specialized feeding structures) develop in almost every adjacent plant cell. Haustoria breach through the plant cell wall but remain separated from the host cytoplasm by extrahaustorial membranes, which are extensions of the plant plasma membrane (Koch and Slusarenko 1990). The intimate interaction between biotrophs and their hosts is influenced by secreted pathogen effector molecules that can be targeted to the plant cell apoplast or translocated into the host cell (Allen et al. 2008; Cabral et al. 2011; Seidl et al. 2011; Sohn et al. 2007). As obligate biotrophic pathogens need living host cells for growth and reproduction, effectors act by modulating plant processes, e.g., suppressing plant defense, without getting recognized or detected by the host's surveillance mechanisms. Pathogen recognition is often associated with host cell death, which is detrimental for completion of the life cycle of biotrophic pathogens (Botella et al. 1998; McDowell et al. 1998; Parker et al. 1997; an der Biezen et al. 2002).

Recently, analysis of the $H$. arabidopsidis genome revealed it encodes $>800$ secreted proteins, many of which are proposed to play a role in the infection process (Seidl et al. 2011). An important family of secreted proteins in $H$. arabidopsidis and other oomycetes is composed of the necrosis and ethyleneinducing peptide 1 (Nep1)-like proteins (NLP) (Baxter et al. 2010; Haas et al. 2009; Tyler et al. 2006). NLP that induce necrosis have been found in many plant pathogens (bacteria, fungi, and oomycetes) (Bailey 1995; Fellbrich et al. 2002; Garcia et al. 2007; Kanneganti et al. 2006; Mattinen et al. 2004; Motteram et al. 2009; Qutob et al. 2002; Veit et al. 2001). Comparative genome analysis among the fully sequenced genomes of the oomycetes Phytophthora sojae, $P$. ramorum, $P$. infestans, and Hyaloperonospora arabidopsidis and the fungi Mycosphaerella graminicola, Magnoporthe grisea, and Fusarium graminearum, revealed that the NLP family in oomycetes is more expanded than in fungal pathogens (Baxter et al. 2010; Cuomo et al. 2007; Dean et al. 2005; Haas et al. 2009; Motteram et al. 2009; Seidl et al. 2011; Tyler et al. 2006). Despite their diverse phylogenetic distribution, NLP share a conserved domain referred to as the NPP1 domain (Fellbrich et al. 2002). A hallmark of the NPP1 domain is a conserved heptapeptide motif "GHRHDWE" in the central region of the protein and the presence of either two or four conserved cysteine residues, which characterize the domain as Type 1 or Type 2, respectively (Gijzen and 
Nurnberger 2006). So far, all oomycete NLP harbor a Type 1 domain, while NLP of bacteria and fungi either have a Type 1 domain, a Type 2 domain, or both.

NLP from different pathogens have been shown to induce tissue necrosis in dicotyledonous plants (Bailey 1995; Fellbrich et al. 2002; Garcia et al. 2007; Kanneganti et al. 2006; Mattinen et al. 2004; Motteram et al. 2009; Qutob et al. 2002, 2006; Veit et al. 2001). Recently, the crystal structure of an NLP of Pythium aphanidermatum $\left(\mathrm{NLP}_{\mathrm{Pya}}\right)$ revealed that this protein has structural similarities to actinoporins, which are pore-forming toxins from marine organisms (Ottmann et al. 2009). NLP are cytolytic toxins that induce necrosis through a permeabilization of the plasma membrane. Although the molecular mechanism by which these proteins cause membrane permeabilization and, thus, necrosis has not been elucidated, some structural and spatial features of NLP proteins have been identified that are required for their cytolytic activity (Fellbrich et al. 2002; Ottmann et al. 2009; Veit et al. 2001). For instance, the necrosisinducing activity of NLP requires an intact protein (significantly truncated versions are inactive) and is dependent on targeting of the protein to the extracellular side of the plant plasma membrane (Fellbrich et al. 2002; Qutob et al. 2006). Furthermore, the necrosis-inducing activity of NLP requires the correct formation of a putative binding pocket and coordinative binding of a $\mathrm{Ca}^{2+}$ ion (Ottmann et al. 2009). A positive role of NLP proteins in phytopathogenicity has been shown for necrotrophic fungal and bacterial pathogens (Amsellem et al. 2002; Mattinen et al. 2004; Ottmann et al. 2009). For the hemibiotrophic pathogens $P$. sojae and $P$. infestans, expression of the necrosis-inducing proteins PsojNIP and PiNPP1 was detected at the infection stages coinciding with the transition from biotrophy to necrotrophy (Kanneganti et al. 2006; Qutob et al. 2002). It was proposed that the expression of these proteins might facilitate the colonization of host tissues during the necrotrophic phase.

Recently, mining the genome of $H$. arabidopsidis identified ten genes belonging to the NLP family (Baxter et al. 2010). Here, we describe the entire HaNLP gene family, including duplicated gene copies and a large number of pseudogenes. Most HaNLP genes showed induced expression at early stages of infection. Strikingly, none of the HaNLP proteins was able to induce necrosis when tested on tobacco or Arabidopsis. Domain swap experiments between the noncytotoxic HaNLP3 and the necrosis-inducing protein PsojNIP allowed the fine mapping of a surface-exposed region, the replacement of which resulted in gain of cytotoxicity of HaNLP3. Our data suggest that the HaNLP family have evolved to become noncytotoxic but, at the same time, have preserved most NLP structural features for their as-yet-unknown biological function during biotrophy.

\section{RESULTS}

\section{The HaNLP gene family.}

The $H$. arabidopsidis genome sequence was mined for $N L P$ sequences. We identified 14 full-length genes, of which ten genes had been previously described (Baxter et al. 2010). The additional four $H a N L P$ sequences are highly homologous to HaNLP4 (for HaNLP4.2 and HaNLP4.3), HaNLP6 (for HaNLP6.2), and HaNLP8 (for HaNLP8.2), suggesting these genes are present in the genome in more than one copy. Furthermore, $15 N L P$ pseudogenes were identified either containing premature stop codons and frame shifts or with only a partial coding sequence (Supplementary Table S1). The positions of the HaNLP genes and pseudogenes within the genomic contigs are shown in Supplementary Figure S1. Quantitative polymerase chain reaction (qPCR) was used to verify the HaNLP copy number on genomic DNA of the sequenced isolate Emoy2, and we confirmed that all but two HaNLP were found to be single-copy genes. We observed that both HaNLP6 and HaNLPS were present in two copies in the genome, confirming the genome assembly (Supplementary Fig. S2). In contrast, only a single HaNLP4 was detected in Emoy2 genomic DNA, instead of the three copies found in the assembled sequence. Detailed analysis of the three HaNLP4 genomic regions showed that these were highly identical over a length $>10 \mathrm{~kb}$ and are possibly the result of misassembly of sequence reads. We conclude that the $H$. arabidopsidis Nep1-like gene family is more expanded than previously described, comprising 12 HaNLP genes and 15 pseudogenes.

To analyze the phylogenetic relationship between the 27 HaNLP sequences identified and other oomycete $N L P$, we used NLP gene models from Phytophthora infestans as well as sequences of other NLP that have previously been shown to induce necrosis (Bailey et al. 1997; Fellbrich et al. 2002; Kanneganti et al. 2006; Qutob et al. 2002; Veit et al. 2001). As shown in Figure 1, all HaNLP sequences (including all pseudogenes) except for HaNLP3 and HaNLP5 cluster together, forming a species-specific clade in the tree. Expanding the phylogenetic tree with $N L P$ genes of $P$. sojae and $P$. ramorum did not change the grouping of the HaNLP family. For reasons of clarity, only the $P$. infestans genes were included in the tree (Fig. 1). Some of the HaNLP-specific branches contain only pseudogenes (e.g., HaNLP-Pseudo3 and HaNLPPseudo10, HaNLP-Pseudo2, HaNLP-Pseudo4, HaNLPPseudo5, and HaNLP-Pseudo7), while others contain genes and pseudogenes (e.g., branches HaNLP8-HaNLP9 and HaNLP1-HaNLP7). Interestingly, the branch containing HaNLP2, HaNLP4, and HaNLP6, has only one pseudogene (HaNLP-Pseudo9), which is highly identical to HaNLP4, suggesting that NLP gene duplications have recently occurred in $H$. arabidopsidis. Taken together, this large species-specific expansion of $H a N L P$ genes suggests that this gene family is the result of recent evolution in $H$. arabidopsidis.

It is worth noting that HaNLP3 and HaNLP5 cluster together with NLP from members of genus Phytophthora, suggesting they represent more ancient genes. Of all HaNLP, HaNLP3 is phylogenetically most closely related to NLP proteins with demonstrated necrosis-inducing activity (Fig. 1) (Baxter et al. 2010). This is also reflected at the protein level with HaNLP3 showing the highest level of protein similarity to PsojNIP.

\section{Features of the $\boldsymbol{H}$. arabidopsidis Nep1-like proteins.}

The predicted HaNLP protein sequences range in size from 173 to 419 amino acids. For all HaNLP proteins, strong putative N-terminal signal peptides (SP) were predicted except for HaNLP3, which had a weaker SignalP score (Fig. 2). The characteristic heptapeptide motif "GHRHDWE" is degenerated in most HaNLP proteins. However, it is fully conserved in HaNLP3 and HaNLP4. The 12 HaNLP have two conserved cysteine residues (Supplementary Fig. S3), which classify the NPP1 domain of these proteins as Type 1, like all other oomycete NLP proteins so-far described (Gijzen and Nurnberger 2006).

Comparison of the primary protein structure of HaNLP proteins with PsojNIP revealed the presence of additional domains at the $\mathrm{N}$ - or C-termini of the predicted HaNLP (Fig. 2). In HaNLP3, there is an additional 23-amino acid domain rich in glutamine residues (26\% Q, named Q-rich domain) between the SP and the NPP1 domain, which has also been observed in other oomycete NLP proteins (Gijzen and Nurnberger 2006). At the N-terminus of HaNLP9 there is a 69-amino acid domain between the SP and the NPP1 domain rich in proline, ser- 
ine, and threonine (together $43 \%$ of the domain composition), which was also identified in other oomycete NLP (Gijzen and Nurnberger 2006). In the additional domain of HaNLP9, NetOGlyc 3.1 (Julenius et al. 2005) predicted 11 potential sites for $O$-glycosylation (Supplementary Fig. S4), a feature not observed in any other HaNLP. $O$-glycosylation sites have been described for $H$. arabidopsidis and Phytophthora elicitins, another class of pathogen-secreted proteins (Cabral et al. 2011; Jiang et al. 2006). The N-terminal domains of HaNLP8 and HaNLP10 (26 and 36 amino acids, respectively) do not share any similarity to known domains. The additional C-terminal domain of HaNLP2 and HaNLP6 both contain repetitive sequences. In HaNLP2, the repeats are composed mainly of SerVal-Glu-Asp (6x), while the degenerate repetitive domain in HaNLP6 has a biased amino-acid composition, being rich in glutamic acid (28\%), serine (21\%), and glutamine (17\%). Both the HaNLP2 and the HaNLP6 C-terminal part are not similar to known domains. HaNLP7 is the smallest of the HaNLP pro- teins (173 amino acids), as it lacks most of the C-terminal domain. However, the main NLP features are present in this protein, including the two cysteine residues and a degenerated heptapeptide motif.

The seven amino-acid residues that are known to be essential for necrosis-inducing activity of NLP proteins are conserved in HaNLP2, HaNLP3, HaNLP4, and HaNLP6. Five of these are involved in cation binding and stabilization, corresponding to amino-acid residues K112, D113, H121, D124, and E126 in PsojNIP, three of which (underlined) are present in the GHRHDWE heptapeptide motif (Ottmann et al. 2009). The other two amino acids important for cytolytic activity correspond to the two cysteine residues that are conserved in all 12 HaNLP (Fellbrich et al. 2002).

\section{HaNLP expression peaks early during infection.}

The expression of the HaNLP genes was monitored to determine at which infection stage they are activated. For this,

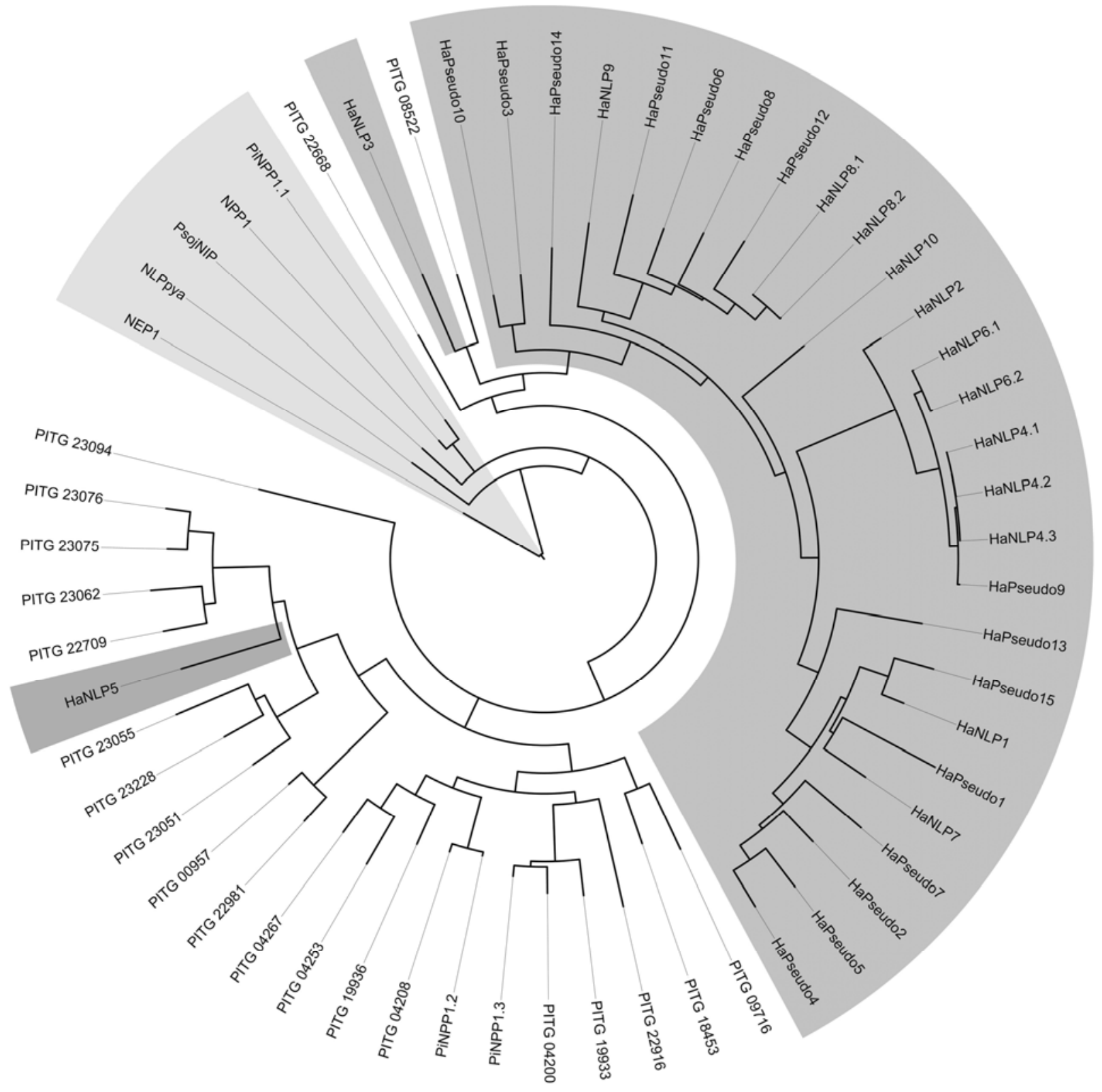

Fig. 1. Phylogenetic relationship of the Hyaloperonospora arabidopsidis necrosis and ethylene-inducing peptide 1 (Nep1)-like protein genes (HaNLP) and pseudogenes (visible in the dark gray background) with NLP of Phytophthora infestans and NLP of other oomycetes that are known to induce necrosis (visible in the lighter gray background). DNA sequences were aligned using ClustalW2, and a Phylogenetic tree was constructed using the maximumlikelihood method of RAxML with 1,000 bootstraps. 
H. arabidopsidis isolate Emoy2 was inoculated on the highly susceptible Arabidopsis line Ws eds1-1, and leaves were sampled at different time points after inoculation (Fig. 3A). At $6 \mathrm{~h}$ postinoculation (hpi), conidiospores germinated and appressoria were formed. Six hours later (12 hpi), penetration hyphae crossed the epidermal layer and haustoria developed. At 1 day postinoculation (dpi), the pathogen formed intercellular hyphae and haustoria, and at $2 \mathrm{dpi}, H$. arabidopsidis colonization of the leaf tissue continued. Abundant intercellular hyphae forming haustoria in neighboring plant cells continued to develop and formed a dense hyphal network at 3 dpi. During the first three days of infection, no conidiospores were formed, confining the analysis to cellular structures of the pathogen that are intimately engaged in the interaction with host cells.

qPCR analysis of HaNLP mRNA levels in the abovedescribed infected plant material revealed high transcript levels

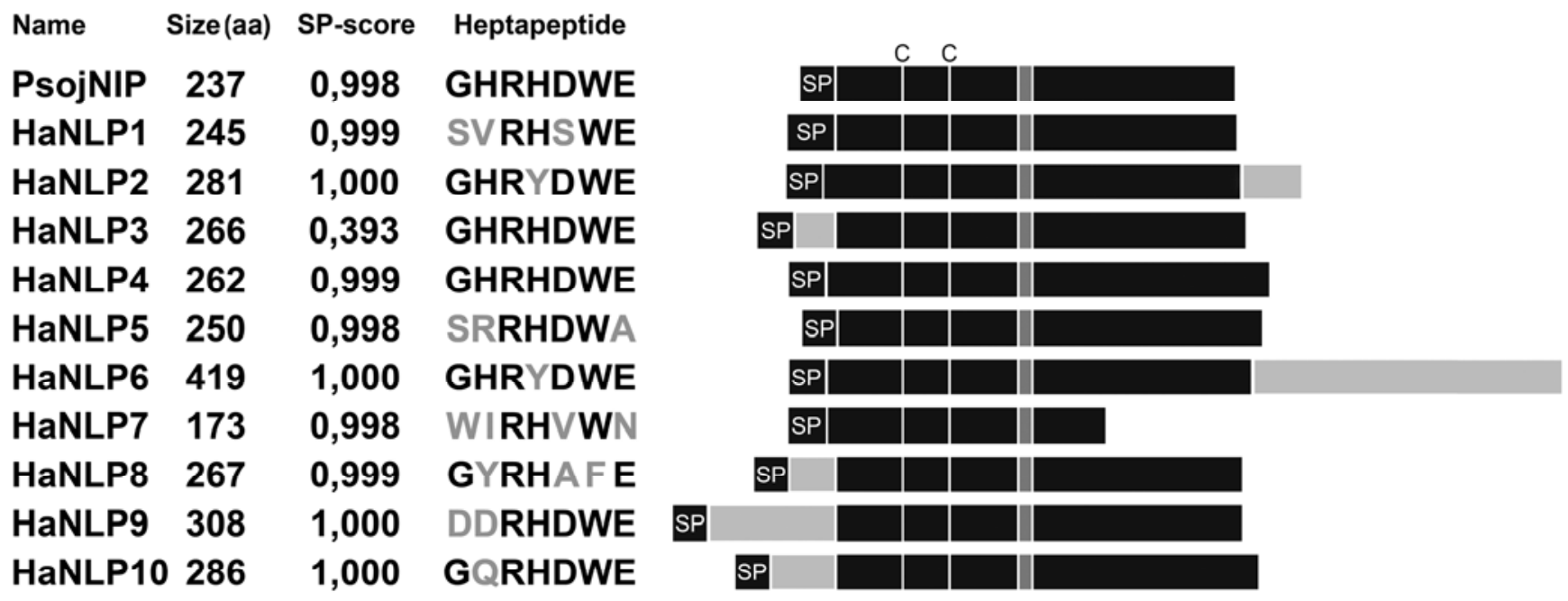

\section{Signal peptide Additional N- or C-terminal domain Heptapeptide motif}

Fig. 2. Features of the 12 Hyaloperonospora arabidopsidis necrosis and ethylene-inducing peptide 1 (Nep1)-like proteins (HaNLP), including the number of amino acids in the full-length protein, SignalP hidden Markov model score, and heptapeptide motif. Due to the high similarity of the HaNLP6 and HaNLP8 copies these are represented as single proteins. In the schematic representation of the primary protein structures, several characteristics are represented, such as the predicted signal peptide (SP), the two conserved cysteine residues (C), the heptapeptide motif, and the presence of additional domains that are not part of the NPP1 domain.
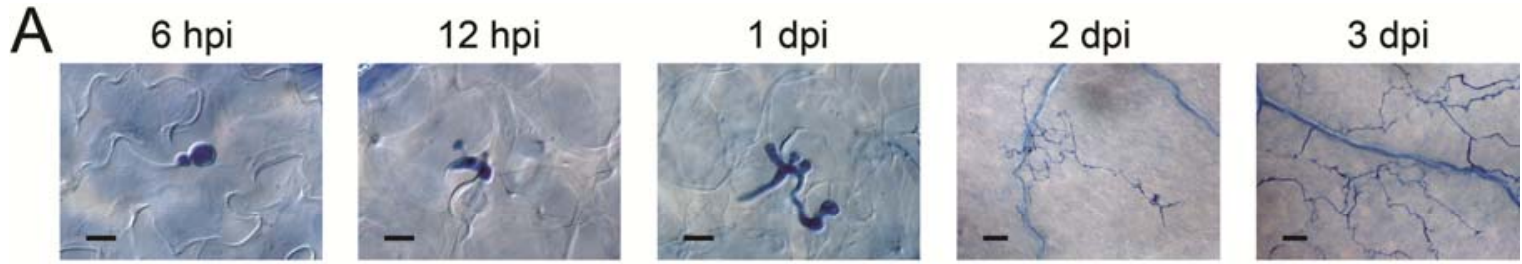

B

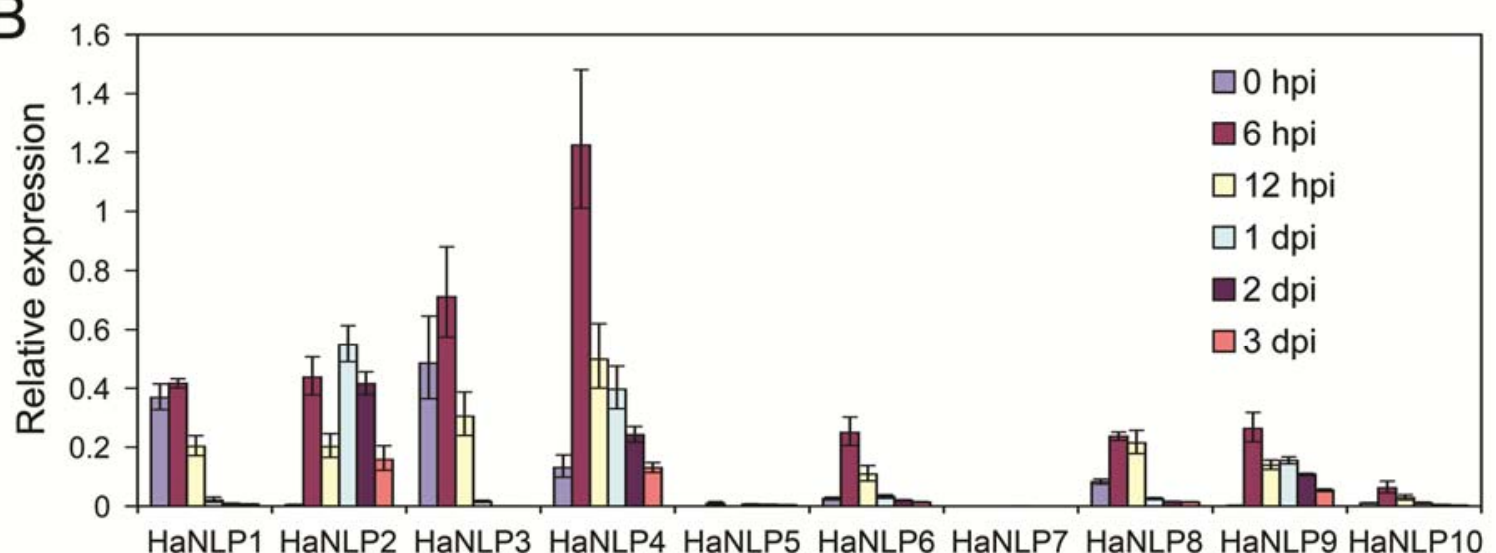

Fig. 3. Expression of Hyaloperonospora arabidopsidis necrosis and ethylene-inducing peptide 1 (Nep1)-like protein genes (HaNLP) during Hyaloperonospora arabidopsidis infection of Arabidopsis plants. A, Trypan blue stainings of Arabidopsis Ws eds1-1 leaves infected with H. arabidopsidis isolate Emoy2 at different timepoints. At $0 \mathrm{~h}$, just after spraying spores on the plants, nonadhering pathogen was washed away during the staining procedure. Scale bars are $10 \mu \mathrm{m}(6$ and $12 \mathrm{~h}$ postinoculation [hpi] and 1 day postinoculation [dpi]) and $50 \mu \mathrm{m}$ ( 2 and $3 \mathrm{dpi})$. B, Relative transcript level of the different $H a N L P$ genes during $H$. arabidopsidis Emoy2 infection of Ws eds1-1 Arabidopsis leaves determined by quantitative-polymerase chain reaction. The expression of the HaNLP genes is represented as fold change relative to the expression of $H$. arabidopsidis ACTIN. Primers used were specific for each gene, except for HaNLP4, HaNLP6, and HaNLP8, which have highly identical variants. The error bars represent the standard deviation of three technical replicates. Similar results were obtained in three independent experiments. 
for most $H a N L P$ genes during the early stages of infection (up to $1 \mathrm{dpi}$ ), whereas expression of HaNLP5, HaNLP7, and HaNLP10 was low or undetectable. Strikingly, for all HaNLP genes with detectable expression, relatively high activation was detected at 6 hpi when appressoria were formed (Fig. 3). Four genes (HaNLP1, HaNLP3, HaNLP4, and HaNLP8) were already expressed in conidiospores before the interaction with the plant host. Based on their temporal expression during infection, the HaNLP genes can be divided into two groups. The first group, comprising HaNLP2, HaNLP4 and HaNLP9, was expressed during the entire infection process while, for the second group (HaNLP1, HaNLP3, HaNLP6, and HaNLP8), expression was strongest at the early stages of infection (up to $12 \mathrm{hpi}$ ).
HaNLP are not phytotoxic.

The fact that $H$. arabidopsidis is an obligate biotroph requiring living host cells raises the question if any of the HaNLP is cytotoxic. To test proteins for necrosis-inducing activity, we transiently expressed the ten different $H a N L P$ coding sequences under control of the $35 \mathrm{~S}$ promoter in Nicotiana tabacum using Agrobacterium tumefaciens-mediated transient expression, a system that has been previously validated to determine necrosis-inducing activity of NLP proteins (Schouten et al. 2008). Transient expression of the different HaNLP genes did not result in any necrotic response (Fig. 4B), with no visible symptoms up to $12 \mathrm{dpi}$. PsojNIP was used as positive control, and it induced visible necrosis of inoculated sites already at 2 dpi.
A

PsojNIP HaNLP3

PSOJNIP HaNLP3 HaNLP3

PSOJNIP HaNLP3

PsojNIP HaNLP3
PsOjNIP

Q-rich region

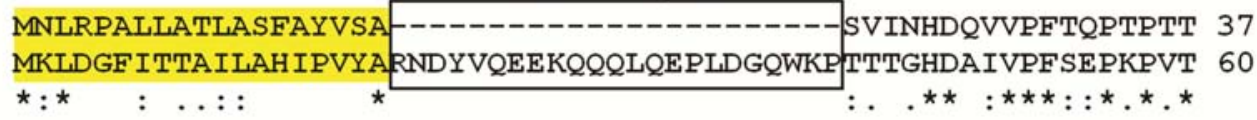

ALQQAAVKYKPQIHISNGCHPYPAVDNNGNTSGGLNPTGSE SAGCKGSGYGTQIYGRAVK 97 ISEKAGVKFKPLLDVNTGCAPYAAVNAEGETSGGLQTSGDPE SGCRGSKYGSQVYGRSTW 120

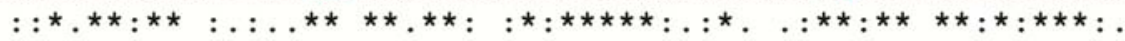

YQGVYAFMYSWYMPKDETLTGLGHRHDWEACVVWVDDIAASSPKIVALSASAHSGYNKYY 157 YNDVWA IMYAWYFPKD SPMLLMGHRHDWENVVVF INDPDEVEPTILGCSTSWHSGY IKYA 180

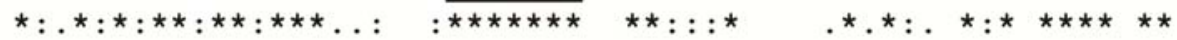

PPSSSYFSGNSAKIDYSSSYVVINHALSATSTAGETQPLIMWDQLTDAARRALEDTDFGD 217 PCPTDS INGSSVMIKYEHSFP-LNHALNITKDAGAYQDLIMWHQMPDLARRALNDTDFGK 239

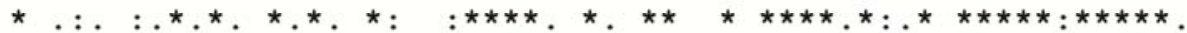

ANVPFKDANFQTKLGNAYYA------- 237 AITPMNDLNFMEKIEAAWPFKTKKDGA 266 * .*: : ** *: * :

$\mathrm{B}$

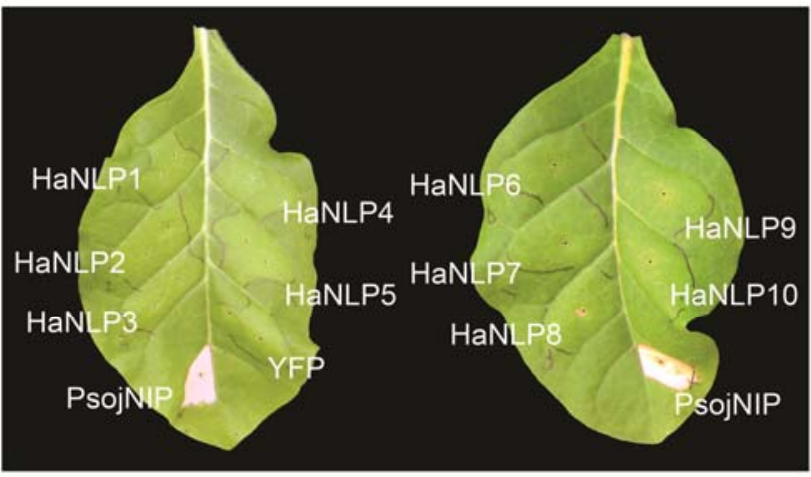

C

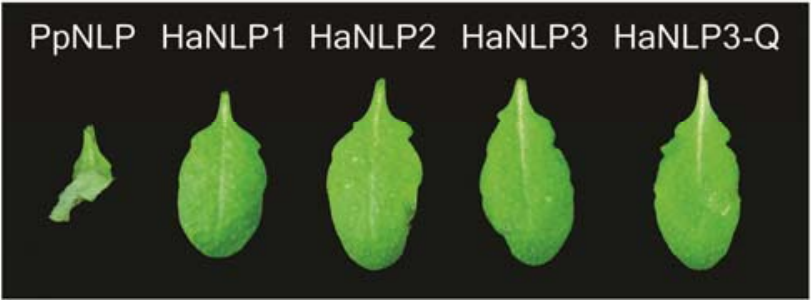

PpNLP HaNLP1 HaNLP2 HaNLP3 HaNLP3-Q
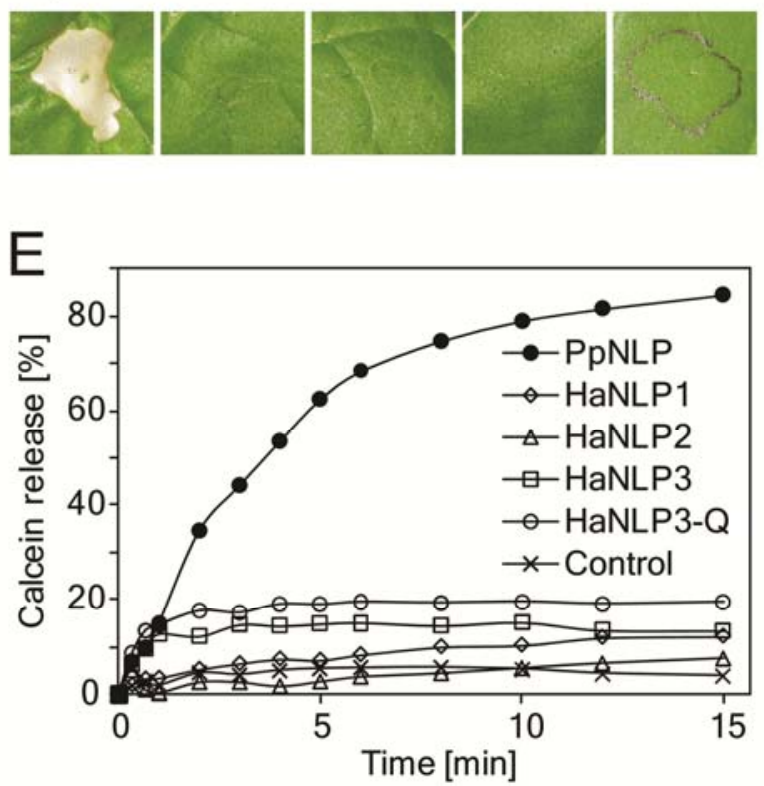

Fig. 4. Hyaloperonospora arabidopsidis necrosis and ethylene-inducing peptide 1 (Nep1)-like proteins (HaNLP) lack necrosis-inducing activity. A, Alignment of PsojNIP and HaNLP3, indicating amino acids previously identified that are important for necrotic activity (indicated in red). Predicted signal peptides, the heptapeptide motif, and Q-rich region are depicted. B, Agrobacterium-mediated transient expression of HaNLP on tobacco leaves (5 days postinoculation [dpi]). No necrotic lesions were induced by expression of HaNLP up to 12 dpi. The HaNLP are numbered 1 to 10 . PsojNIP was used as positive control and YFP as a negative control. C, Leaves from Arabidopsis or D, tobacco were infiltrated with $2 \mu \mathrm{M}$ Phytophthora parasitica NLP as positive control and HaNLP1, HaNLP2, HaNLP3, and a HaNLP3 variant without the Q-rich region (HaNLP3-Q). E, Membrane permeabilization assay. PpNLP was used as positive control and induced release of calcein from plasma membrane vesicles obtained from Arabidopsis. Treatment with purified HaNLP1, HaNLP2, HaNLP3, and a HaNLP3 variant without the Q-rich region HaNLP3-Q were not able to induce calcein release. One representative experiment of three yielding similar results is shown. 
To verify the reproducibility of this result, we analyzed the effect of HaNLP3, the most likely HaNLP that could have necrosis-inducing activity (discussed above; Fig. 4A), in complementary experiments. Purified HaNLP3 (Supplementary Fig. S5) and, as a positive control, a cytolytic NLP of $P$. parasitica PpNLP (previously named NPP1) (Fellbrich et al. 2002) were infiltrated into leaves of Arabidopsis thaliana Col-0 (Fig. 4C) and Nicotiana tabacum (Fig. 4D). While the positive control PpNLP $(2 \mu \mathrm{M})$ induced necrosis within $12 \mathrm{~h}$ following infiltration, HaNLP3 failed to induce necrotic symptoms under the same experimental conditions within $48 \mathrm{~h}$ following infiltration. HaNLP1 $(2 \mu \mathrm{M})$ and HaNLP2 $(2 \mu \mathrm{M})$ were also included in these experiments and did not show necrosis-inducing activity. Increasing the concentration of the HaNLP proteins up to $20 \mu \mathrm{M}$ also did not lead to an induction of necrosis (data not shown).

We tested whether HaNLP3 was able to disrupt plasma membranes, a feature observed for cytolytic NLP proteins (Ottmann et al. 2009). Plasma membrane vesicles obtained from Arabidopsis leaves were loaded with a fluorescent dye (calcein), and membrane damage triggered by NLP was measured as dye release (Fig. 4E). HaNLP1, HaNLP2, and HaNLP3 (20 nM) were not able to permeabilize membranes, nor were higher concentrations up to $200 \mathrm{nM}$. This is in contrast to the necrosisinducing PpNLP that disintegrated vesicles at $20 \mathrm{nM}$ within 5 min of protein application.

\section{Structure-function analysis of HaNLP3.}

Compared with the PsojNIP protein, the HaNLP3 protein differs at two important points: i) the $\mathrm{N}$-terminus that has a weak SP prediction score and, directly connected to that, ii) an additional Q-rich region N-terminal of the NPP1-domain (Fig. 1 and 4A). To verify if these two features of the HaNLP3 protein could be related to the lack of the necrosis-inducing activity, chimeras were created between the HaNLP3 and PsojNIP proteins (Fig. 5A).

We compared the timing and appearance of necrosis in $N$. tabacum leaves infiltrated with A. tumefaciens expressing the different constructs (Fig. 5B and C). All chimeras produced stable protein products in planta (Supplementary Fig. S6). The necrosis-inducing activity of PsojNIP was reduced when the predicted SP was exchanged with that of HaNLP3 (fusion 1), which is in agreement with the lower SP score of HaNLP3. Nevertheless, the fact that fusion 1 still induces necrosis indicates that the HaNLP3 SP can secrete the mature PsojNIP protein from plant cells. Also the addition of the Q-rich region to PsojNIP (fusion 2) resulted in a reduction in necrosis-inducing activity. Fusion 3, which contains both the SP and Q-rich region of HaNLP3 fused to PsojNIP, was no longer able to induce necrosis, possibly as a result of additive negative effects on PsojNIP cytolytic activity. To test whether the weak SP and the inhibitory Q-rich region of HaNLP3 are the cause of its lack of necrosis-inducing activity, the mature HaNLP3 protein was fused to the strong PsojNIP SP, either with or without the Q-rich region (fusions 4 and 5, respectively). Both fusion proteins failed to induce necrosis, indicating that features of the HaNLP3 NPP1-domain are responsible for the lack of necrosis-inducing activity.

We confirmed this observation in a complementary assay in which purified recombinant HaNLP3 protein without the Qrich region was directly infiltrated into tobacco and Arabidopsis leaves. The recombinant HaNLP3 proteins failed to cause leaf necrosis (at concentrations up to $20 \mu \mathrm{M}$ ) (Fig. 4C and D), whereas the positive control PpNLP induced strong necrosis at a concentration of $2 \mu \mathrm{M}$. A second measure of NLP activity is the increase in permeability of plant membranes, as determined by the release of fluorescent calcein from preloaded vesicles made from Arabidopsis membranes. Recombinant HaNLP3 without the Q-rich region did not result in release of the fluorochrome, whereas adding PpNLP protein resulted in a steady release of calcein from the membrane vesicles (Fig. 4E). Taken together, these findings show that mature HaNLP3 with or without the Q-rich region does not induce necrosis.

\section{Gain of toxicity by exchange} of an exposed domain in HaNLP3.

In an attempt to identify domains in the HaNLP3 protein that prevent it from inducing necrosis, chimeras were made by exchanging sequences between PsojNIP and fusion 5 that contains the SP of PsojNIP fused to the HaNLP3 NPP1-domain without the Q-rich region (Fig. 6A). All chimeras produced stable protein products in planta. As shown in Figure 6, chimeras created by swapping either the $\mathrm{N}$-terminal or the $\mathrm{C}$ terminal domain (fusions 6 and 7) revealed gain of necrosis activity solely by the construct containing the $\mathrm{N}$-terminus of PsojNIP fused to 160 amino acids of the C-terminus of HaNLP3 (fusion 7) (Fig. 6B and C), indicating that the N-

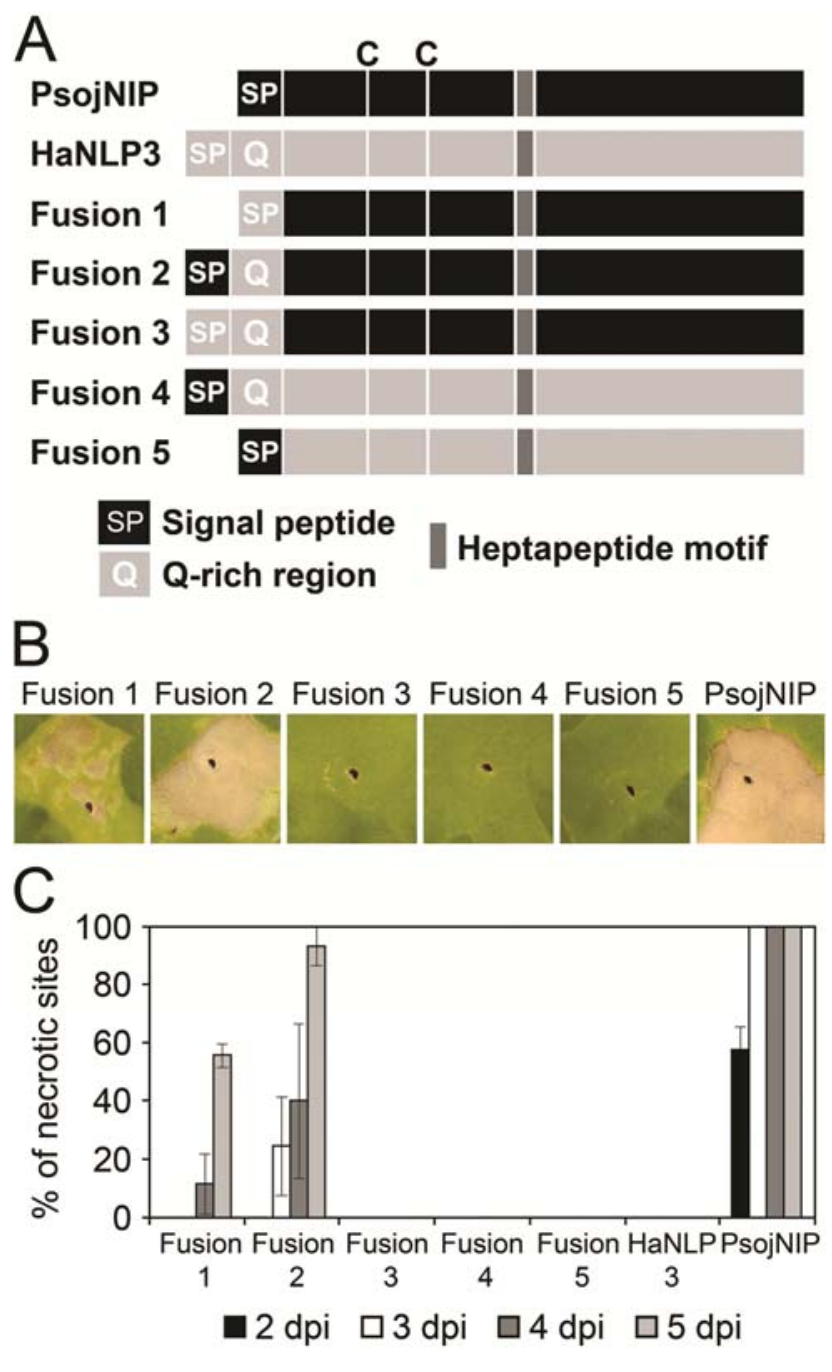

Fig. 5. The signal peptide (SP) and Q-rich region are not responsible for the lack of necrosis-inducing activity of HaNLP3. A, Schematic representation of chimeras (fusions 1 to 5) made between HaNLP3 and PsojNIP. B, Agrobacterium-mediated transient expression of fusion constructs on tobacco leaves. Photos were taken at 5 days postinoculation (dpi). C, Frequencies of inoculated sites showing necrosis observed in tobacco leaves from 2 to $5 \mathrm{dpi}$. Frequencies were calculated as percentages of necrotic sites of the total number of inoculations per tested construct. The data originated from three independent experiments with a total of 45 sites inoculated per construct. 
terminal domain of HaNLP3 prevents the induction of necrosis. Importantly, fusion 7 also shows that the large C-terminal region of 160 amino acids of HaNLP3, including the domain surrounding the heptapeptide motif, is functionally equivalent to that of PsojNIP. To narrow down the differential effect in the N-terminal region of HaNLP3, the PsojNIP region in fusion 7 was further split into two parts at the first conserved cysteine residue (fusions 8 and 9). However, neither fusion 8 nor fusion 9 were able to induce necrosis, suggesting that the two N-terminal regions of PsojNIP are both required for its cytotoxic activity.

When comparing the amino acid sequence of the N-terminal region, up to the first conserved cysteine residue of HaNLP3, and several NLP that induce necrosis (region divided in boxes in Figure 7A), two conserved regions (Fig. 7Aa and c) can be distinguished. The sequences between these regions (Fig. 7Ab) is highly diversified in all necrosis-inducing NLP and, therefore, not likely to be an important structural region. Indeed, we observed that fusion 10, which has the HaNLP3 sequence for this diversified region $b$ (Fig. 7A) shows comparable necrosisinducing activity to fusion 7 , which has the sequence of PsojNIP for this region.

To define whether region a or region c (Fig. 7A) might be preventing the induction of necrosis, we initially analyzed the position of the corresponding regions in the resolved $3 \mathrm{D}$ structure of NLPpya of Pythium aphanidermatum (Ottmann et al. 2009). In the protein structure (Fig. 7B), region a is located very closely to the region between the two conserved cysteine residues, a domain that we also found to be important for necrosis-inducing activity (fusion 8). Comparison of the sequence of region a between HaNLP3 and several necrosis-inducing proteins (Fig. 7A) revealed four amino acid residues before the conserved $\mathrm{H}$ and $\mathrm{D}$ amino acids that are very different between HaNLP3 (TTTG, mostly hydrophilic) and the necrosis-inducing proteins (containing hydrophobic amino acids). We engineered fusion 9 by replacing the four amino acids TTTG of HaNLP3 with those of PsojNIP (SVIN), resulting in fusion 11. Strikingly, fusion 11 was able to induce necrosis to similar levels as observed for fusion 7 . We conclude that a region of HaNLP3, corresponding to a large exposed region in NLPpya but consisting of two separate stretches in the primary amino acid sequence of HaNLP3, prevents the protein from inducing necrosis.

\section{DISCUSSION}

In this paper, we describe the characterization of Nep1-like proteins of the obligate biotrophic pathogen Hyaloperonospora arabidopsidis. We observed that, besides the 10 genes reported in the $H$. arabidopsidis genome (Baxter et al. 2010), several additional pseudogenes and fragmented sequences are present in the $H$. arabidopsidis genome. We also identified additional copies of HaNLP6 and HaNLP8, based on blast searches. These extra copies were confirmed by qPCR analysis on genomic DNA of $H$. arabidopsidis Emoy2. Considering these new findings, the HaNLP family comprises a total of 12 genes and 15 pseudogenes in isolate Emoy2 and is more expanded in $H$. arabidopsidis than initially described.

HaNLP genes encode predicted secreted proteins that are likely targeted to the host apoplast during the infection process. Interestingly, although the SP score of HaNLP3 is low, a clear SP cleavage site was predicted. It is possible that the algorithms used for prediction of SP sequences are not accurate for oomycete sequences. We showed the functionality of the HaNLP3 SP in plants by fusing this sequence to the mature PsojNIP protein. This chimera was able to induce necrosis, a plant response that can only be observed if PsojNIP is localized in the host apoplast (Qutob et al. 2002). However, a decrease in the number of necrotic sites and longer incubation period was observed, indicating that although the SP of HaNLP3 works as a secretion signal, it is not as efficient as the native SP of PsojNIP when secreted by tobacco cells. None of the HaNLP were detected by proteomics to be present in apoplastic fluid isolated from $H$. arabidopsidis-infected Arabidopsis leaves, whereas other secreted pathogen proteins were identified (N. Boot and G. Van den Ackerveken, unpublished data). The expression of HaNLP genes early during the infection process could explain a low protein abundance at later stages of infection (around $5 \mathrm{dpi}$ ) when apoplastic fluid was isolated. Alternatively, the HaNLP proteins could have mem-
A

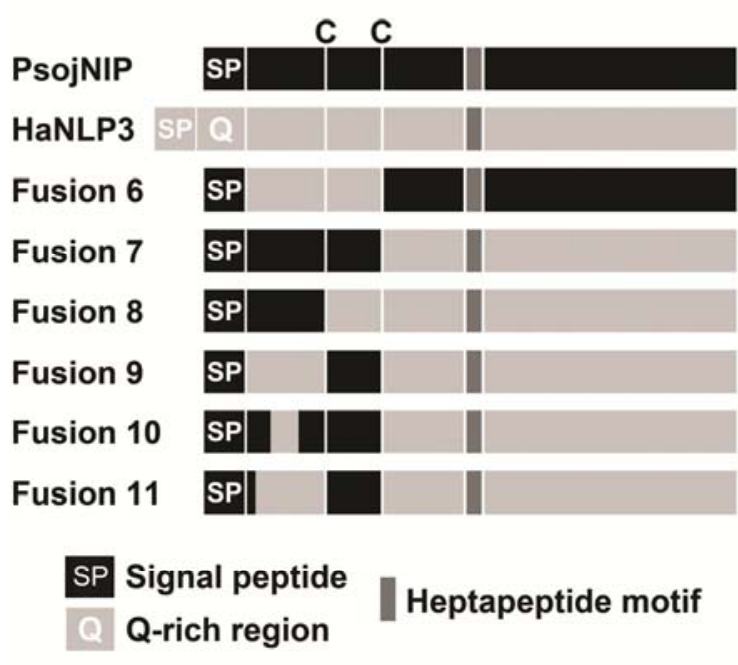

Fusion 6 Fusion 7 Fusion 8 Fusion 9 Fusion 10 Fusion 11 PsojNIP
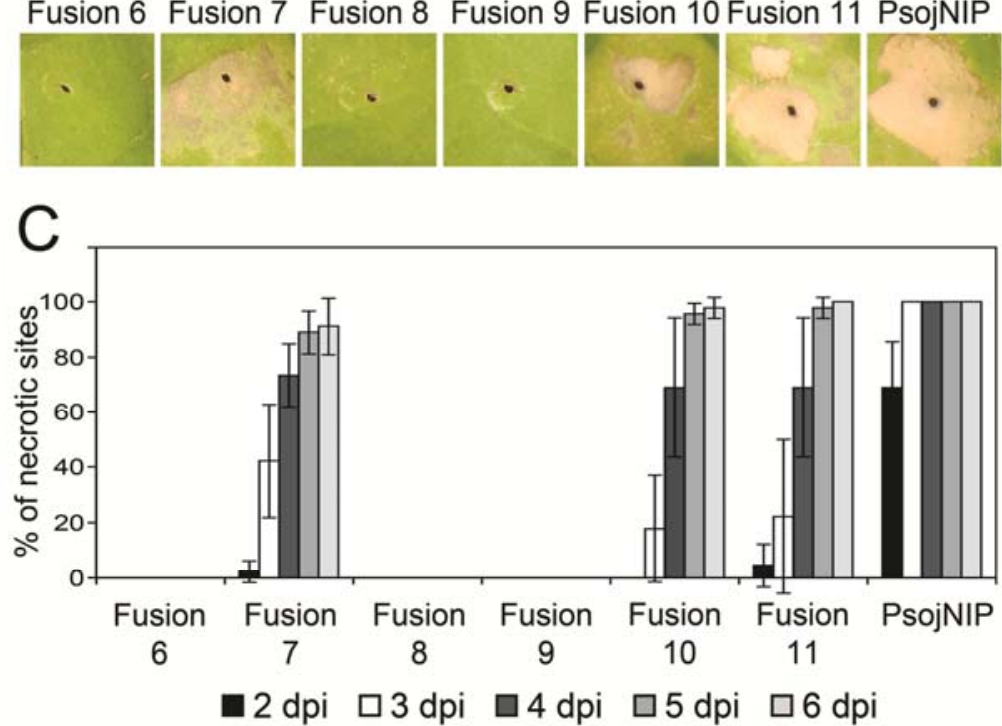

Fig. 6. Swapping of two regions in HaNLP3 restored necrosis-inducing activity. A, Schematic representation of chimeras made between HaNLP3 and PsojNIP. B, Agrobacterium-mediated transient expression of fusion constructs on tobacco leaves. Photos were taken at 5 days postinoculation (dpi). C, Frequencies of inoculated sites showing necrosis observed in tobacco leaves from 2 to 6 dpi. Frequencies were calculated as percentages of necrotic sites of the total number of inoculations per tested construct. Three independent experiments were performed with a total of 45 sites inoculated per construct. 
brane-binding activity that would prevent them from being washed from the plant cells during apoplastic fluid isolation.

According to our results, the expression of the HaNLP genes during infection is generally higher at early infection stages and is concomitant with appressorium formation (6 hpi). It is tempting to speculate that the nontoxic HaNLP protins may function in attachment or primary contact between pathogen and host. However, some HaNLP genes are expressed during the entire infection process, while others are expressed mainly at the initial infection stages. Besides, some of these genes are already expressed in conidiospores, prior to the initiation of infection. In hemibiotrophic organisms, such as the oomycete Phytophthora sojae, cytotoxic NLP expression is associated with the appearance of disease symptoms on infected plants as the pathogen transitions from a biotrophic to a necrotrophic phase at later stages of infection (Qutob et al. 2002). In the case of $P$. infestans, the toxic NPP1.1 is expressed at late stages of colonization of tomato, similar to the above-described NLP of $P$. sojae (Kanneganti et al. 2006). Interestingly, like the HaNLP family, the noncytolytic PiNPP1.3 is constitutively expressed during the biotrophic phase. Taken together, these results suggest that, regarding the function, it is likely that at least two different classes of NLP can be identified: i) toxic NLP that act during the transition from biotrophy to necrotrophy and ii) nontoxic NLP that might have a role in the establishment of biotrophic interactions.

The NPP1 domain of the HaNLP proteins contains two conserved cysteine residues and therefore resembles other oomycete
NLP (Gijzen and Nurnberger 2006). Besides the cysteine residues, a characteristic feature of the NPP1 domain is a central region with a conserved heptapeptide motif "GHRHDWE." This sequence is not conserved in the HaNLP proteins, except for HaNLP3 and HaNLP4. Sequence alignments, including the HaNLP proteins and PsojNIP, revealed the presence of additional $\mathrm{N}$ - or $\mathrm{C}$-terminal domains in some HaNLP predicted protein sequences. HaNLP3 has an extra hydrophilic domain rich in glutamine residues inserted between the SP cleavage site and the NPP1 domain. A chimera generated by adding the Q-rich region to the N-terminus of PsojNIP was still able to induce necrosis (Fig. 5). Our results suggest that oomycete proteins having an additional N-terminal hydrophilic domain are still potential necrosis-inducing proteins.

Also at the N-terminus, a potential $O$-glycosylated domain was found only in HaNLP9. $O$-glycosylation has been predicted for other secreted oomycete effectors (Jiang et al. 2006; Cabral et al. 2011) and were also found in two PiNLP (PITG_22668 and PITG_08522), which are most similar to HaNLP (Fig. 1).

Phylogenetic comparison with other oomycete NLP sequences (Fig. 1) revealed that the HaNLP family form a large cluster unrelated to other oomycete $N L P$. The evolutionary expansion of a $H a N L P$-specific group suggests that these genes are likely to be important for the biology of this highly specialized pathogen, perhaps pointing to a special role for these proteins in this species. Although the presence of a specific HaNLP cluster has been previously described (Baxter et
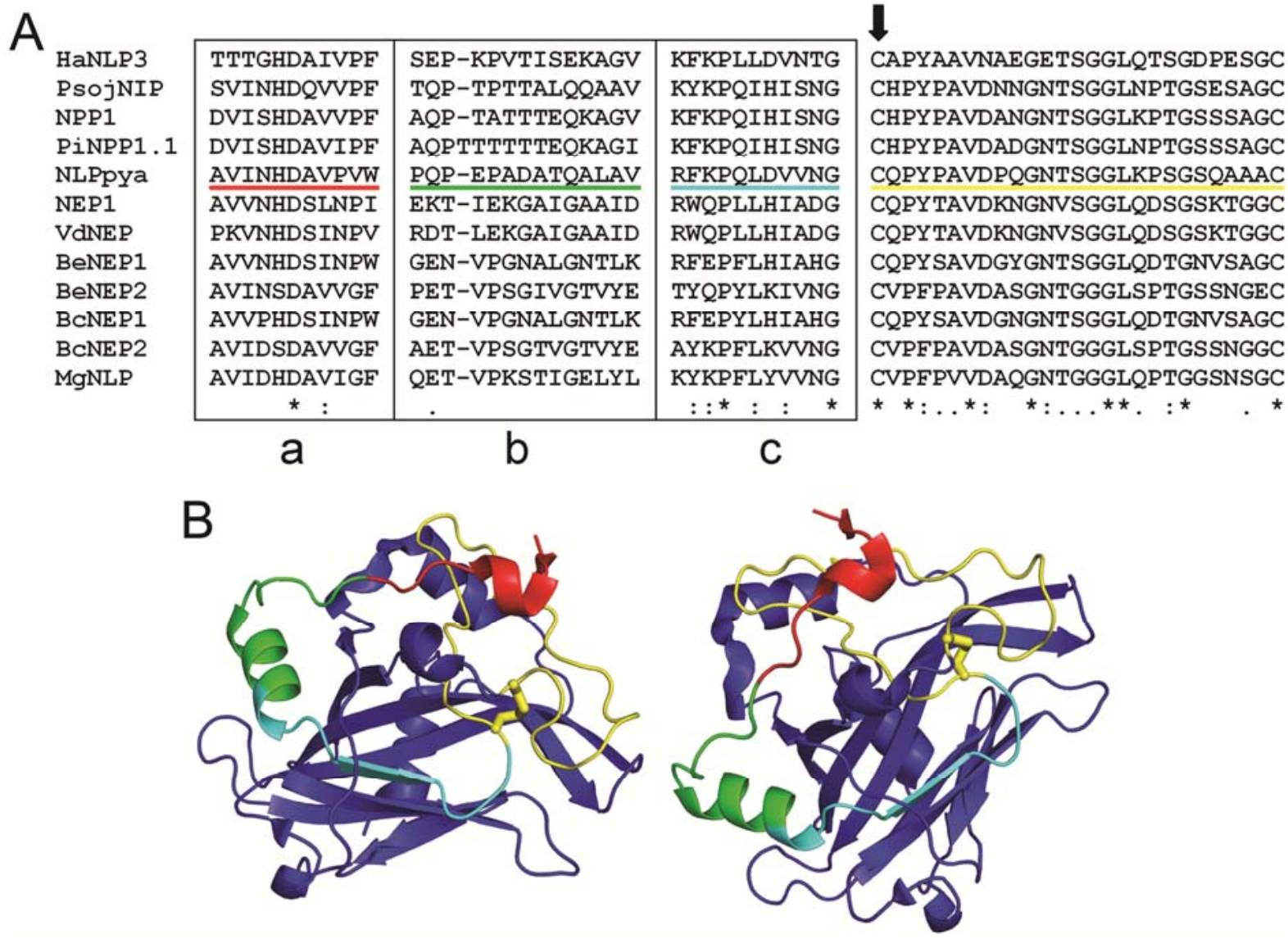

Fig. 7. Exposed domain is important for necrosis activity. A, Alignment of N-terminal domain of HaNLP3 with other necrosis and ethylene-inducing peptide 1 (Nep1)-like proteins (NLP) (PsojNIP: AF320326 [Qutob et al. 2002]; PiNPP1.1: AY961417 [Kanneganti et al. 2006]; NLPpya: AF179598 [Veit et al. 2001]; NEP1: AAC97382 [Bailey 1995]; NPP1: AF352031 [Fellbrich et al. 2002]; VdNEP: AY524789 [Wang et al. 2004]; BeNEP1: DQ211827 [Staats et al. 2007]; BeNEP2: DQ211828 [Staats et al. 2007]; BcNEP1: DQ211824 [Schouten et al. 2008]; BcNEP2: DC211825 [Schouten et al. 2008]; MgNLP: EGP82712 [Motteram et al. 2009]). The region upstream of the first cysteine residue (indicated by the arrow) is divided in three parts (a, b, and c) based on conservation of amino acids. Region $b$ is highly variable among the analyzed proteins while regions a and c are more conserved. B, $3 \mathrm{D}$ structure of the NLP from Pythium aphanidermatum, indicating the position of regions a (red), b (green), and c (cyan), the two conserved cysteines and the region between the conserved cysteines (yellow). 
al. 2010), here, we showed that addition of several other HaNLP sequences, including pseudogenes, partial sequences, and additional copies, revealed a further expansion of the H. arabidopsidis-specific cluster, indicating that recent duplications are responsible for the increase in the number of $H a N L P$ sequences. HaNLP3 and HaNLP5 group together with other oomycete sequences, suggesting that these two genes were present in a common oomycete ancestor and could have a different function in comparison with other HaNLP genes. Notably, HaNLP3 was found in a clade containing several necrosis-inducing proteins of different oomycete pathogens, and therefore, this protein is the most likely $H a N L P$ gene that could have retained necrosis-inducing activity (Fig. 1) (Baxter et al. 2010).

Domain swaps between HaNLP3 and PsojNIP uncovered regions within NLP proteins that were, thus far, unknown to be important for necrotic activity. Previous studies identified several amino acids important for necrosis induction (Fellbrich et al. 2002; Ottmann et al. 2009). As all these residues are conserved in HaNLP3, another region is impairing its ability to induce necrosis. Indeed, HaNLP3 with the N-terminus of PsojNIP exhibits gain of cytolytic activity (Fig. 6, fusion 7). Fine mapping of the $\mathrm{N}$-terminal region revealed that two domains are important for gain of necrosis activity of HaNLP3. Based on sequence comparison of toxic NLP and the previously published 3D structure of the NLP of Pythium aphanidermatum (Ottmann et al. 2009), we were able to identify two regions on an exposed domain of HaNLP3 that, when swapped by PsojNIP sequences, resulted in gain of NLP toxicity.

Although previous reports have described organisms containing only necrosis-inducing NLP (e.g., Botrytis cinerea [Schouten et al. 2008], Pectobacterium carotovorum subsp. carotovorum [Mattinen et al. 2004], Mycosphaerella graminicola [Motteram et al. 2009]) and organisms containing both necrosis-inducing and non-necrosis inducing NLP (e.g., Phytophthora infestans [Kanneganti et al. 2006]), H. arabidopsidis is the first organism for which all present NLP are noncytotoxic. This is not surprising, since $H$. arabidopsidis is an obligate biotrophic pathogen that needs living host cells for completion of its life cycle. The identification of the recently expanded family of nontoxic NLP in $H$. arabidopsidis, together with the finding that HaNLP3 has adapted to become noncytotoxic but at the same time has preserved most NLP structural features, suggests that the HaNLP have evolved to function during biotrophic infection of plants.

\section{MATERIALS AND METHODS}

\section{Plant and pathogen growth conditions, infection, and staining.}

$H$. arabidopsidis isolate Emoy2 was propagated on Oy-0 plants at a 7-day interval. Arabidopsis thaliana mutant Ws eds $1-1$, used in pathogen-challenge experiments, was grown at $22^{\circ} \mathrm{C}$ with $10 \mathrm{~h}$ of light and a relative humidity of $75 \%$. Infections were performed by spraying $H$. arabidopsidis spore suspension $\left(5 \times 10^{4}\right.$ spores per milliliter) on 14-day-old Ws eds $1-1$ seedlings to the point of imminent run-off. Plants were subsequently covered with a transparent sealed lid and were incubated at $16^{\circ} \mathrm{C}$ with $10 \mathrm{~h}$ of light. Samples were collected at 0 , $6,12,24,48$, and 72 hpi. Infections were visualized by trypan blue staining as previously described (Van Damme et al. 2005), and images were made by differential interference contrast microscopy. Three independent timecourse experiments were performed. Nicotiana tabacum seeds were germinated in 30$\mathrm{ml}$ pots and plants were grown for 1 week at $22^{\circ} \mathrm{C}$ with $10 \mathrm{~h}$ of light and $70 \%$ relative humidity. The plants were then transplanted to 200-ml pots and were kept at enough distance from each other to avoid damage to the leaves.
NLP identification and bioinformatic analysis.

Blast queries (TblastN and blastN) (Altschul et al. 1990) using the ten HaNLP sequences published previously (Baxter et al. 2010) and PsojNIP (AF320326) (Qutob et al. 2002) were performed against the $H$. arabidopsidis genome assembly (V8.3 at Virginia Bioinformatics Institute) and trace files at the National Center for Biotechnology Information to identify pseudogenes and copy number variants and to map the genes within the contigs. For the identification of pseudogenes, blast hits were manually inspected. SP predictions were performed by SignalP V3.0 (Bendtsen et al. 2004).

To collect NLP sequences of Phytophthora infestans all gene models from the Broad Institute were used in TBlastN and BlastN searches, using PsojNIP as a query. Of the identified PiNLP sequences, only those encoding full-length proteins were maintained. The obtained $N L P$ sequences were aligned using ClustalW2 (Larkin et al. 2007) and the phylogenetic tree was constructed using RAxML and iTOL.

\section{HaNLP cloning and construction of recombinant Agrobacterium tumefaciens.}

The HaNLP genes were PCR-amplified from Emoy2 genomic DNA and from cDNA obtained from Emoy2-infected Arabidopsis leaves to verify the presence of introns and gene expression. Since no introns were observed, Emoy2 genomic DNA was used to amplify the HaNLP genes, using the primers listed in Supplementary Table S2. For each amplification, PCR products were excised and purified from gel, using Illustra GFX PCR DNA and gel band purification kit (GE Healthcare, Buckinghamshire, U.K.). Purified PCR products were cloned in the pENTR/D-TOPO vector, using a directional TOPO cloning reaction (Invitrogen, Bleiswijk, The Netherlands). The clone insert was sequence-verified using standard vector primers (M13F and M13R-pUC). The insert DNA was transferred to the Gateway destination vector pB7WG2 (Plant Systems Biology, University of Ghent, Belgium) by LR recombination (Invitrogen), and clones were PCR-verified for correct insert size. HA-tagged HaNLP were constructed by multisite gateway cloning, using LR clonase plus (Invitrogen) and the vector pB7m34GW (Plant Systems Biology). The three entry clones used in a multisite LR reaction were a $35 \mathrm{~S}$ CaMV (Cauliflower mosaic virus) promoter (flanked by AttB4 and attB1 sites), the gene of interest (pENTR/D-TOPO clones without stop codon), and a 3xHA epitope tag (flanked by AttB2 and AttB3). The HA-tagged constructs were sequence-verified using standard vector primer M13F. Entry clones containing the $35 \mathrm{~S}$ CaMV promoter and 3xHA epitope tag were provided by $\mathrm{B}$. Scheres (Utrecht University, The Netherlands).

Three independent clones were independently electro-transformed into A. tumefaciens C58C1_pGV2260. The presence of inserts of expected size in A. tumefaciens clones was verified by PCR. For the Agrobacterium-mediated transient expression assay, three independent $A$. tumefaciens clones (derived from each of the three destination clones) were used. The PsojNIP cDNA clone was provided by $\mathrm{M}$. Gijzen (Agriculture and Agri-Food Canada, Ottawa, Canada). Primers were used for amplification of full-length PsojNIP, which was further cloned in the same way as the HaNLP genes. YFP cloned in pENTR/D-TOPO was provided by J. E. Parker (Max Planck Institute, Cologne, Germany).

\section{Nucleic acid extraction and cDNA synthesis.}

Total RNA was extracted from ground leaf material, using the RNeasy plant mini kit (Qiagen, Venlo, The Netherlands), and was treated with the RNase-free DNase set (Qiagen), following the manufacturer's instructions. Genomic DNA was isolated from $H$. arabidopsidis isolate Emoy2 spores using the 
DNeasy plant mini kit (Qiagen). Total RNA and DNA were quantified using a NanoDrop spectrophotometer (ND-1000; De Meern, The Netherlands). Plasmid DNA was purified from Escherichia coli cultures, using GenElute plasmid miniprep kit (Sigma, Zwijndrecht, The Netherlands). cDNA synthesis was performed with $4.5 \mu \mathrm{g}$ of Total RNA, Superscript-III reverse transcriptase (Invitrogen), and oligo(dT)15 (Promega, Utrecht, The Netherlands).

\section{qPCR analysis.}

H. arabidopsidis isolate Emoy2 genomic DNA was used to determine gene copy number by real-time PCR. Gene-specific primers that amplified PCR products between 99 and $101 \mathrm{bp}$ at the $3^{\prime}$ end of the transcript were designed. Amplification reactions $(25 \mu \mathrm{l})$ were performed in triplicate, each with a different amount of input genomic DNA (3, 6, and $12 \mathrm{ng}), 10 \mu \mathrm{M}$ of each primer, and $12.5 \mu$ l of master mix (Power SYBR Green I, Applied Biosystems, Bleiswijk, The Netherlands). Copy number was determined as a ratio of the estimated copies of each $H a N L P$ to the reference gene $H$. arabidopsidis ACTIN.

For measurement of transcribed mRNA levels, cycle thresholds were determined in triplicate per transcript in three biological replicas, using the same primers and reaction conditions described for genomic DNA. The expression of each gene was determined as fold change relative to the average cycle threshold values of the control gene $H$. arabidopsidis ACTIN. The qPCR parameters were $2 \mathrm{~min}$ at $50^{\circ} \mathrm{C}, 10 \mathrm{~min}$ at $95^{\circ} \mathrm{C}$, followed by 40 cycles of $15 \mathrm{~s}$ at $95^{\circ} \mathrm{C}$ and $60 \mathrm{~s}$ at $60^{\circ} \mathrm{C}$, ending with $15 \mathrm{~s}$ at $95^{\circ} \mathrm{C}, 15 \mathrm{~s}$ at $60^{\circ} \mathrm{C}$, and $15 \mathrm{~s}$ at $95^{\circ} \mathrm{C}$. The specificity of the PCR was determined by melting curve analysis of the amplified products, using the standard method installed in the system.

\section{Generation of domain swap clones.}

To generate domain swap clones, PsojNIP and HaNLP3 cloned in pENTR/D-TOPO were initially used as template. Fusions 1 to 9 were created by overlap PCR, using two rounds of PCR amplification. In independent reactions, specific domains were amplified from HaNLP3 and PsojNIP, using primers for these genes and fusion primers. The PCR products were purified as described before, and the combined PCR products were then used as template in a second PCR reaction. The PCR amplifications were performed using Phusion Taq polymerase, following the manufacture's instruction. The first and second PCR reactions were performed with 10 and 20 cycles, respectively. The obtained products were cloned in $\mathrm{pENTR/D-}$ TOPO and were further processed as described above.

\section{Site-directed mutagenesis.}

Fusions 10 and 11 were made by site-directed mutagenesis of gateway entry clones, using $5^{\prime}$ phosphorylated primers and plasmid DNA as template. Nucleotides were added at the $5^{\prime}$ end of both forward and reverse primers. The PCR-product was ligated back to its circular form using T4 DNA ligase (Fermentas, St. Leon-Rot, Germany), and were subsequently transformed into $E$. coli $\mathrm{DH} 5 \alpha$.

\section{Agrobacterium-mediated transient expression assays.}

Recombinant $A$. tumefaciens were grown overnight at $28^{\circ} \mathrm{C}$ with the appropriate antibiotics. Cells were harvested by centrifugation and were resuspended to a final concentration corresponding to an optical density at $600 \mathrm{~nm}$ of 0.8 in a solution containing $10 \mathrm{mM}$ morpholineethanesulfonic acid (MES), $\mathrm{pH}$ 5.6, $10 \mathrm{mM} \mathrm{MgCl}_{2}$, and $0.07 \mathrm{mM}$ acetosyringone. Cultures were incubated at room temperature for $4 \mathrm{~h}$ before infiltration. The samples were infiltrated into leaves of 4- to 5-week-old $N$. tabacum plants using a 1-ml syringe.

\section{Protein expression analysis.}

Total protein extracts were prepared by grinding four leaf disks ( $8 \mathrm{~mm}$ in diameter) per sample of $N$. tabacum plants $48 \mathrm{~h}$ after infiltration. Samples were resuspended in $100 \mu \mathrm{l}$ of $2 \times$ Laemmli loading buffer, were boiled for $5 \mathrm{~min}$, and were centrifuged to remove cell debris. Proteins were separated by sodium dodecyl sulfate (SDS)-polyacrylamide gel electrophoresis on $12 \%$ gel and were transferred onto nitrocellulose membranes. Membranes were incubated with rat anti-HA antibody (Roche Applied Science, Almere, The Netherlands) or with a polyclonal NPP1 antibody (Fellbrich et al. 2002). Antibody-bound proteins were detected using either a goat anti-rat immunoglobulin $\mathrm{G}$ (IgG)-HRP conjugate (Santa Cruz Biotechnolgy sc2006, Heidelberg, Germany) or a goat anti-rabbit IgG-HRP (Cell Signaling Technology, Leiden, The Netherlands), using a chemiluminescence detection kit (SuperSignal West Femto chemiluminescent substrate, Pierce, Landsmeer, The Netherlands).

\section{Heterologous expression of HaNLP in Pichia pastoris, protein purification, and leaf infiltration.}

The cDNAs encoding for HaNLP1, HaNLP2, and HaNLP3 without SP were amplified via PCR (using primers HaNLP1forEcoRI, HaNLP1revNotI, HaNLP2forEcoRI, HaNLP2revNotI, HaNLP3forEcoRI, and HaNLP3revNotI) and were cloned into the secretory expression plasmid pPIC9K. For deletion of the Q-rich domain in HaNLP3, the 27 amino acids next to the SP of HaNLP3 were deleted, according to the QuikChange II XL site-directed mutagenesis kit instructions (Stratagene, Amstelveen, The Netherlands), using primers Alpha-HaNLP3-Qfor and Alpha-HaNLP3-Qrev. Secretory expression of HaNLP in Pichia pastoris GS115 was performed according to the Multi-Copy Pichia expression kit instructions (Invitrogen). Purification of the protein from the culture medium of Pichia pastoris was achieved by ion-exchange chromatography followed by gel filtration. Culture medium containing HaNLP was dialyzed against $20 \mathrm{mM} \mathrm{NaAc}, \mathrm{pH} 4.7$, and was applied to a HiTrap SP FF 5-ml column for HaNLP1 or against $20 \mathrm{mM}$ Tris- $\mathrm{HCl}, \mathrm{pH} 8.5$, and applied to a HiTrap Q FF 5-ml column (GE Healthcare) for HaNLP2, HaNLP3, and HaNLP3-Q. These columns were equilibrated in the same buffer used for dialysis. After extensive washing, bound proteins were eluted with a linear gradient of 0 to $500 \mathrm{mM} \mathrm{KCl}$ in equilibration buffer. Following gel electrophoretic analysis, protein-containing fractions were pooled and were subjected to a HiLoadTM 16/60 Superdex 75 column (GE Healthcare) equilibrated in $20 \mathrm{mM}$ Tris, $\mathrm{pH} 8$, and $150 \mathrm{mM} \mathrm{KCl}$. Upon visual inspection on an SDS gel, protein-containing fractions were pooled and dialyzed against deionized sterile distilled water. Purified NLP ( 2 to $20 \mu \mathrm{M}$ ) or mock solution were infiltrated abaxially into leaves of $N$. tabacum cv. Samsun NN (4 to 6 weeks old) or Arabidopsis thaliana Col-0 (4 to 5 weeks old) grown at $22^{\circ} \mathrm{C}$ (15 h light).

\section{Preparation and permeabilization of calcein-loaded plasma membrane vesicles.}

Plant plasma membranes were prepared by phase partitioning of microsomal fractions (Larsson et al. 1994), using Dextran and polyethylene glycol in a $6.4 \%$ concentration $(\mathrm{wt} / \mathrm{wt})$ and $3 \mathrm{mM} \mathrm{KCl}$. For preparation of calcein-loaded vesicles, plasma membranes (500 $\mu \mathrm{g}$ protein) were sonified (30 min on ice, 20-s pulse on, 20-s pulse off, amplitude $25 \%$ ) in the presence of calcein $(60 \mathrm{mM}, \mathrm{pH} 7.0)$. The external calcein was removed by gel filtration, using Sephadex G-75 (Sigma) medium column equilibrated in $20 \mathrm{mM}$ Tris, $\mathrm{pH} 8.5,140 \mathrm{mM} \mathrm{NaCl}$, and $1 \mathrm{mM}$ EDTA. Permeabilization of the vesicles $(1 \mathrm{ng}$ of protein per microliter) induced by 20 to $200 \mathrm{nM}$ NLP was 
assayed at room temperature in $20 \mathrm{mM}$ MES, pH 5.8, $140 \mathrm{mM}$ $\mathrm{NaCl}$ by measuring fluorescence (excitation $485 \mathrm{~nm}$, emission $520 \mathrm{~nm}$ ) in a microplate reader (Sirius HT Injector; MWG Biotech, Ebersberg Germany. The percentage of calcein release (R) was calculated according to the equation $\mathrm{R}=\left(\mathrm{F}_{\text {meas }}-\mathrm{F}_{\text {init }}\right) /$ $\left(F_{\max }-F_{\text {init }}\right) \times 100$, where $F_{\text {meas }}, F_{\text {init }}$, and $F_{\text {max }}$ are the measured, initial, and maximal fluorescence, respectively. $\mathrm{F}_{\max }$ was obtained by the addition of Triton X-100 to $0.5 \%$ (vol $/ \mathrm{vol}$ ) final concentration at the end of each measurement. The experiments were repeated three times with similar results.

\section{ACKNOWLEDGMENTS}

We thank K. Posthuma, J. Elberse, T. Sliedrecht, and T. van Kuyk for their technical assistance and initial contributions related to the HaNLP project, and M. Seidl for his assistance in constructing the phylogenetic tree. This work was funded by a VIDI innovational research grant (GvdA) from The Netherlands Organization for Scientific Research (NWO), the ERA-NET Plant Genomics consortium 'Effectoromics' (GvdA, AC), and by the Centre for Biosystems Genomics (GvdA, SO).

\section{LITERATURE CITED}

Agrios, G. N. 2005. Plant Pathology. Academic Press, New York.

Allen, R. L., Meitz, J. C., Baumber, R. E., Hall, S. A., Lee, S. C., Rose, L. E., and Beynon, J. L. 2008. Natural variation reveals key amino acids in a downy mildew effector that alters recognition specificity by an Arabidopsis resistance gene. Mol. Plant Pathol. 9:511-523.

Altschul, S. F., Gish, W., Miller, W., Myers, E. W., and Lipman, D. J. 1990. Basic local alignment search tool. J. Mol. Biol. 215:403-410.

Amsellem, Z., Cohen, B. A., and Gressel, J. 2002. Engineering hypervirulence in a mycoherbicidal fungus for efficient weed control. Nat. Biotechnol. 20:1035-1039.

Bailey, B. A. 1995. Purification of a protein from culture filtrates of Fusarium oxysporum that induces ethylene and necrosis in leaves of Erythroxylum coca. Phytopathology 85:1250-1255.

Bailey, B. A., Jennings, J. C., and Anderson, J. D. 1997. The 24-kDa protein from Fusarium oxysporum f. sp. erythroxyli: Occurrence in related fungi and the effect of growth medium on its production. Can. J. Microbiol. 43:45-55.

Baxter, L., Tripathy, S., Ishaque, N., Boot, N., Cabral, A., Kemen, E., Thines, M., Ah-Fong, A., Anderson, R., Badejoko, W., Bittner-Eddy, P., Boore, J. L., Chibucos, M. C., Coates, M., Dehal, P., Delehaunty, K., Dong, S., Downton, P., Dumas, B., Fabro, G., Fronick, C., Fuerstenberg, S. I., Fulton, L., Gaulin, E., Govers, F., Hughes, L., Humphray, S., Jiang, R. H., Judelson, H., Kamoun, S., Kyung, K., Meijer, H., Minx, P., Morris, P., Nelson, J., Phuntumart, V., Qutob, D., Rehmany, A., Rougon-Cardoso, A., Ryden, P., Torto-Alalibo, T., Studholme, D., Wang, Y., Win, J., Wood, J., Clifton, S. W., Rogers, J., Van den Ackerveken, G., Jones, J. D., McDowell, J. M., Beynon, J., and Tyler, B. M. 2010. Signatures of adaptation to obligate biotrophy in the Hyaloperonospora arabidopsidis genome. Science 330:1549-1551.

Bendtsen, J. D., Nielsen, H., von Heijne, G., and Brunak, S. 2004. Improved prediction of signal peptides: SignalP 3.0. J. Mol. Biol. 340:783-795.

Botella, M. A., Parker, J. E., Frost, L. N., Bittner-Eddy, P. D., Beynon, J. L., Daniels, M. J., Holub, E. B., and Jones, J. D. 1998. Three genes of the Arabidopsis RPP1 complex resistance locus recognize distinct Peronospora parasitica avirulence determinants. Plant Cell 10:1847-1860.

Cabral, A., Stassen, J. H., Seidl, M. F., Bautor, J., Parker, J. E., and Van den Ackerveken, G. 2011. Identification of Hyaloperonospora arabidopsidis transcript sequences expressed during infection reveals isolatespecific effectors. PLoS One 6:e19328. Published online.

Cuomo, C. A., Guldener, U., Xu, J. R., Trail, F., Turgeon, B. G., Di Pietro, A., Walton, J. D., Ma, L. J., Baker, S. E., Rep, M., Adam, G., Antoniw, J., Baldwin, T., Calvo, S., Chang, Y. L., Decaprio, D., Gale, L. R., Gnerre, S., Goswami, R. S., Hammond-Kosack, K., Harris, L. J., Hilburn, K., Kennell, J. C., Kroken, S., Magnuson, J. K., Mannhaupt, G., Mauceli, E., Mewes, H. W., Mitterbauer, R., Muehlbauer, G., Munsterkotter, M., Nelson, D., O'Donnell, K., Ouellet, T., Qi, W., Quesneville, H., Roncero, M. I., Seong, K. Y., Tetko, I. V., Urban, M., Waalwijk, C., Ward, T. J., Yao, J., Birren, B. W., and Kistler, H. C. 2007. The Fusarium graminearum genome reveals a link between localized polymorphism and pathogen specialization. Science 317:1400-1402.

Dean, R. A., Talbot, N. J., Ebbole, D. J., Farman, M. L., Mitchell, T. K., Orbach, M. J., Thon, M., Kulkarni, R., Xu, J. R., Pan, H., Read, N. D., Lee, Y. H., Carbone, I., Brown, D., Oh, Y. Y., Donofrio, N., Jeong, J. S., Soanes, D. M., Djonovic, S., Kolomiets, E., Rehmeyer, C., Li, W.,
Harding, M., Kim, S., Lebrun, M. H., Bohnert, H., Coughlan, S., Butler, J., Calvo, S., Ma, L. J., Nicol, R., Purcell, S., Nusbaum, C., Galagan, J. E., and Birren, B. W. 2005. The genome sequence of the rice blast fungus Magnaporthe grisea. Nature 434:980-986.

Fellbrich, G., Romanski, A., Varet, A., Blume, B., Brunner, F., Engelhardt, S., Felix, G., Kemmerling, B., Krzymowska, M., and Nurnberger, T. 2002. NPP1, a Phytophthora-associated trigger of plant defense in parsley and Arabidopsis. Plant J. 32:375-390.

Garcia, O., Macedo, J. A., Tiburcio, R., Zaparoli, G., Rincones, J., Bittencourt, L. M., Ceita, G. O., Micheli, F., Gesteira, A., Mariano, A. C., Schiavinato, M. A., Medrano, F. J., Meinhardt, L. W., Pereira, G. A., and Cascardo, J. C. 2007. Characterization of necrosis and ethyleneinducing proteins (NEP) in the basidiomycete Moniliophthora perniciosa, the causal agent of witches' broom in Theobroma cacao. Mycol. Res. 111:443-455.

Gijzen, M., and Nurnberger, T. 2006. Nep1-like proteins from plant pathogens: Recruitment and diversification of the NPP1 domain across taxa. Phytochemistry 67:1800-1807.

Haas, B. J., Kamoun, S., Zody, M. C., Jiang, R. H., Handsaker, R. E., Cano, L. M., Grabherr, M., Kodira, C. D., Raffaele, S., Torto-Alalibo, T., Bozkurt, T. O., Ah-Fong, A. M., Alvarado, L., Anderson, V. L., Armstrong, M. R., Avrova, A., Baxter, L., Beynon, J., Boevink, P. C., Bollmann, S. R., Bos, J. I., Bulone, V., Cai, G., Cakir, C., Carrington, J. C., Chawner, M., Conti, L., Costanzo, S., Ewan, R., Fahlgren, N., Fischbach, M. A., Fugelstad, J., Gilroy, E. M., Gnerre, S., Green, P. J., Grenville-Briggs, L. J., Griffith, J., Grunwald, N. J., Horn, K., Horner, N. R., Hu, C. H., Huitema, E., Jeong, D. H., Jones, A. M., Jones, J. D., Jones, R. W., Karlsson, E. K., Kunjeti, S. G., Lamour, K., Liu, Z., Ma, L., Maclean, D., Chibucos, M. C., McDonald, H., McWalters, J., Meijer, H. J., Morgan, W., Morris, P. F., Munro, C. A., O'Neill, K., OspinaGiraldo, M., Pinzon, A., Pritchard, L., Ramsahoye, B., Ren, Q., Restrepo, S., Roy, S., Sadanandom, A., Savidor, A., Schornack, S., Schwartz, D. C., Schumann, U. D., Schwessinger, B., Seyer, L., Sharpe, T., Silvar, C., Song, J., Studholme, D. J., Sykes, S., Thines, M., van de Vondervoort, P. J., Phuntumart, V., Wawra, S., Weide, R., Win, J., Young, C., Zhou, S., Fry, W., Meyers, B. C., van West, P., Ristaino, J., Govers, F., Birch, P. R., Whisson, S. C., Judelson, H. S., and Nusbaum, C. 2009. Genome sequence and analysis of the Irish potato famine pathogen Phytophthora infestans. Nature 461:393-398.

Jiang, R. H., Tyler, B. M., Whisson, S. C., Hardham, A. R., and Govers, F. 2006. Ancient origin of elicitin gene clusters in Phytophthora genomes. Mol. Biol. Evol. 23:338-351.

Julenius, K., Molgaard, A., Gupta, R., and Brunak, S. 2005. Prediction, conservation analysis, and structural characterization of mammalian mucin-type O-glycosylation sites. Glycobiology 15:153-164.

Kanneganti, T. D., Huitema, E., Cakir, C., and Kamoun, S. 2006. Synergistic interactions of the plant cell death pathways induced by Phytophthora infestans Nepl-like protein PiNPP1.1 and INF1 elicitin. Mol. Plant-Microbe Interact.19:854-863.

Koch, E., and Slusarenko, A. 1990. Arabidopsis is susceptible to infection by a downy mildew fungus. Plant Cell 2:437-445.

Larkin, M. A., Blackshields, G., Brown, N. P., Chenna, R., McGettigan, P. A., McWilliam, H., Valentin, F., Wallace, I. M., Wilm, A., Lopez, R., Thompson, J. D., Gibson, T. J., and Higgins, D. G. 2007. ClustalW and ClustalX version 2. Bioinformatics 23:2947-2948.

Larsson, C., Sommarin, M., and Widell, S. 1994. Isolation of highly purified plant plasma membranes and separation of inside-out and rightside-out vesicles. Methods Enzymol. 228:451-469.

Mattinen, L., Tshuikina, M., Mäe, A., and Pirhonen, M. 2004. Identification and characterization of Nip, necrosis-inducing virulence protein of Erwinia carotovora subsp. carotovora. Mol. Plant-Microbe Interact.17:1366-1375.

McDowell, J. M., Dhandaydham, M., Long, T. A., Aarts, M. G., Goff, S., Holub, E. B., and Dangl, J. L. 1998. Intragenic recombination and diversifying selection contribute to the evolution of downy mildew resistance at the RPP8 locus of Arabidopsis. Plant Cell 10:1861-1874.

Motteram, J., Küfner, I., Deller, S., Brunner, F., Hammond-Kosack, K. E., Nürnberger, T., and Rudd, J. J. 2009. Molecular characterization and functional analysis of $M g N L P$, the sole NPP1 domain-containing protein, from the fungal wheat leaf pathogen Mycosphaerella graminicola. Mol. Plant-Microbe Interact.22:790-799.

Ottmann, C., Luberacki, B., Kufner, I., Koch, W., Brunner, F., Weyand, M., Mattinen, L., Pirhonen, M., Anderluh, G., Seitz, H. U., Nurnberger, T., and Oecking, C. 2009. A common toxin fold mediates microbial attack and plant defense. Proc. Natl. Acad. Sci. U.S.A. 106:10359-10364.

Parker, J. E., Coleman, M. J., Szabo, V., Frost, L. N., Schmidt, R., van der Biezen, E. A., Moores, T., Dean, C., Daniels, M. J., and Jones, J. D. 1997. The Arabidopsis downy mildew resistance gene RPP5 shares similarity to the toll and interleukin-1 receptors with $\mathrm{N}$ and L6. Plant Cell 9:879-894 
Qutob, D., Kamoun, S., and Gijzen, M. 2002. Expression of a Phytophthora sojae necrosis-inducing protein occurs during transition from biotrophy to necrotrophy. Plant J. 32:361-373.

Qutob, D., Kemmerling, B., Brunner, F., Kufner, I., Engelhardt, S., Gust, A. A., Luberacki, B., Seitz, H. U., Stahl, D., Rauhut, T., Glawischnig, E., Schween, G., Lacombe, B., Watanabe, N., Lam, E., Schlichting, R., Scheel, D., Nau, K., Dodt, G., Hubert, D., Gijzen, M., and Nurnberger, T. 2006. Phytotoxicity and innate immune responses induced by Nep1like proteins. Plant Cell 18:3721-3744.

Schouten, A., van Baarlen, P., and van Kan, J. A. 2008. Phytotoxic Nep1-like proteins from the necrotrophic fungus Botrytis cinerea associate with membranes and the nucleus of plant cells. New Phytol. 177:493-505.

Seidl, M. F., Van den Ackerveken, G., Govers, F., and Snel, B. 2011. A domain-centric analysis of oomycete plant pathogen genomes reveals unique protein organization. Plant Physiol. 155:628-644.

Sohn, K. H., Lei, R., Nemri, A., and Jones, J. D. 2007. The downy mildew effector proteins ATR1 and ATR13 promote disease susceptibility in Arabidopsis thaliana. Plant Cell 19:4077-4090.

Staats, M., Van Baarlen, P., Schouten, A., and Van Kan, J. A. 2007. Functional analysis of NLP genes from Botrytis elliptica. Mol. Plant Pathol. 8:209-214.

Tyler, B. M., Tripathy, S., Zhang, X., Dehal, P., Jiang, R. H., Aerts, A., Arredondo, F. D., Baxter, L., Bensasson, D., Beynon, J. L., Chapman, J., Damasceno, C. M., Dorrance, A. E., Dou, D., Dickerman, A. W., Dubchak, I. L., Garbelotto, M., Gijzen, M., Gordon, S. G., Govers, F., Grunwald, N. J., Huang, W., Ivors, K. L., Jones, R. W., Kamoun, S., Krampis, K., Lamour, K. H., Lee, M. K., McDonald, W. H., Medina, M., Meijer, H. J., Nordberg, E. K., Maclean, D. J., Ospina-Giraldo, M.
D., Morris, P. F., Phuntumart, V., Putnam, N. H., Rash, S., Rose, J. K., Sakihama, Y., Salamov, A. A., Savidor, A., Scheuring, C. F., Smith, B. M., Sobral, B. W., Terry, A., Torto-Alalibo, T. A., Win, J., Xu, Z., Zhang, H., Grigoriev, I. V., Rokhsar, D. S., and Boore, J. L. 2006. Phytophthora genome sequences uncover evolutionary origins and mechanisms of pathogenesis. Science 313:1261-1266.

Van Damme, M., Andel, A., Huibers, R. P., Panstruga, R., Weisbeek, P. J., and Van den Ackerveken, G. 2005. Identification of Arabidopsis loci required for susceptibility to the downy mildew pathogen Hyaloperonospora parasitica. Mol. Plant-Microbe Interact.18:583-592.

van der Biezen, E. A., Freddie, C. T., Kahn, K., Parker, J. E., and Jones, J. D. 2002. Arabidopsis RPP4 is a member of the RPP5 multigene family of TIR-NB-LRR genes and confers downy mildew resistance through multiple signalling components. Plant J. 29:439-451.

Veit, S., Worle, J. M., Nurnberger, T., Koch, W., and Seitz, H. U. 2001. A novel protein elicitor (PaNie) from Pythium aphanidermatum induces multiple defense responses in carrot, Arabidopsis, and tobacco. Plant Physiol. 127:832-841.

Wang, J. Y., Cai, Y., Gou, J. Y., Mao, Y. B., Xu, Y. H., Jiang, W. H., and Chen, X. Y. 2004. VdNEP, an elicitor from Verticillium dahliae, induces cotton plant wilting. Appl. Environ. Microbiol. 70:4989-4995.

\section{AUTHOR-RECOMMENDED INTERNET RESOURCES}

The Broad Institute website: www.broadinstitute.org Interactive Tree of Life (iTOL) tool: itol.embl.de Virginia Bioinformatics Institute V8.3 database: vmd.vbi.vt.edu 